\title{
Bariatrik Cerrahi Planlanan Hastaların Yeme Bağımlılığı, Depresyon ve Beslenme Durumunun Değerlendirilmesi
}

\author{
Evaluation of Eating Addiction, Depression and Nutritional Status of Patients Planned for \\ Bariatric Surgery
}

İdil Akdemir ${ }^{1}$, Esra Köseler Beyaz ${ }^{2}$

Geliş tarihi/Received: 30.07.2021 • Kabul tarihi/Accepted: 29.12.2021

\section{ÖZET}

Amaç: $\mathrm{Bu}$ araştırma; bariatrik cerrahi planlanan hastalarda yeme bağımlılığı, depresyon ve beslenme durumunun değerlendirilmesi amacıyla planlanıp yürütülmüştür.

Bireyler ve Yöntem: Çalışmaya, bariatrik cerrahi için başvurmuş, 127 gönüllü birey (78 kadın, 49 erkek) katılmıştır. Bireylere, anket formu uygulanmış ve üç günlük besin tüketim kayıtları ve antropometrik ölçümleri alınmıştır. Bireylerin, yeme bağımlılığı, Yale Yeme Bağımlılığı Ölçeği ve depresyon durumları ise Beck Depresyon Ölçeği ile değerlendirilmiştir.

Bulgular: Önerilen günlük alım miktarlarına göre, bireylerin günlük diyetle aldıkları potasyum miktarı tüm bireylerde yetersiz, pantotenik asitin ise kadınlarda yetersiz olduğu saptanmıştır. Beck Depresyon Ölçeği puan ortalamasının,

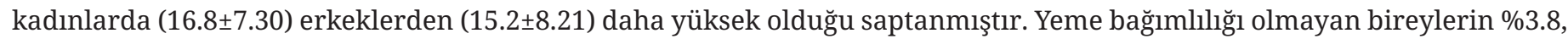
yeme bağımlılığı olan bireylerin ise \%4.3 oranında şiddetli depresyon yaşadıkları belirlenmiştir.

Sonuç: Bariatrik cerrahinin operasyon şansını ve hastaların yaşam kalitelerini arttırmak adına operasyon öncesi beslenme eksikliklerinin giderilmesi, depresyon ve yeme bağımlılı̆̆ gibi semptomların belirlenmesi ve tedavilerine yönelik düzenlemelerin yapılması oldukça önemlidir.

Anahtar kelimeler: Obezite, bariatrik cerrahi, depresyon, yeme bağımlılı̆̆l, besin ögesi eksikliği

\begin{abstract}
Aim: This study was planned and conducted in order to evaluate food addiction, depression and nutritional status in patients undergoing bariatric surgery.

Subjects and Method:127 volunteer adults (78 female, 49 male) who applied for bariatric surgery participated in the study. A questionnaire was applied to the individuals and the food consumption records for three consecutive days and anthropometric measurements of the individuals were taken. Food addiction of the individuals was assessed using the Yale Food Addiction Scale. Depression status of individuals was evaluated with Beck Depression Inventory.

Results: According to the recommended dietary allowances, it has been determined that the potassium intake of individuals was insufficient in all individuals, pantothenic acid was found to be insufficient in women. The mean Beck Depression Inventory score was found to be higher in females $(16.8 \pm 7.30)$ than in males $(15.2 \pm 8.21)$. It was determined that $3.8 \%$ of

1. Başkent Üniversitesi, Sağlık Bilimleri Fakültesi, Beslenme ve Diyetetik Bölümü, Ankara, Türkiye • (1) https://orcid.org/0000-0003-0693-0121

2. İletişim/Correspondence: Başkent Üniversitesi, Sağlık Bilimleri Fakültesi, Beslenme ve Diyetetik Bölümü, Ankara, Türkiye E-posta: koseler@baskent.edu.tr • 이 https://orcid.org/0000-0001-7713-7871
\end{abstract}


individuals without food addiction and 4.3\% of individuals with food addiction experienced severe depression.

Conclusion: In order to increase the chance of operation of bariatric surgery and the quality of life of patients, it is very important to eliminate dietary deficiencies before the operation, to determine symptoms such as depression and food addiction, and to make arrangements for their treatment.

Keywords: Obesity, bariatric surgery, depression, food addiction, nutrient deficiency

\section{GíRIŞ}

Obezite tüm dünyada yaygın olarak görülen ve halk sağlığını küresel olarak tehdit eden kronik bir hastalıktır (1). Obezite; kardiyovasküler hastalık, inme, hipertansiyon, kanser, tip 2 diyabet, dislipidemi, üreme bozuklukları, nörolojik ve psikiyatrik hastalıklar gibi sağlık sorunlarına neden olmaktadır (2).

Obezitenin tedavisinde, öncelikle tıbbi beslenme tedavisi ve fiziksel aktivite gibi yaşam tarzı değişiklikleri denenmelidir. Sonuç alınamadığı takdirde medikal tedavi ve cerrahitedavi de obezitenin tedavi seçenekleri arasında yer almaktadır. Son zamanlarda, obezite tedavisinde cerrahi müdahale seçenekleri daha yaygın hale gelmiştir. Bariatrik cerrahi, obezite ile ilişkili birçok komorbiditenin iyileşmesini ve remisyonunu, etkili vücut ağırlığı kaybını, yaşam kalitesinde iyileşmeyi ve yaşam süresinin uzamasını sağlayan bir tedavi yöntemidir (3).

Yeme bağımlılığı, aşırı yemek yemeye dolayısıyla fazla enerji alımına bağlı obeziteye neden olan bir faktördür (4). Bariatrik cerrahi adaylarında; yeme bağımlılığı prevalansını Meule et al. (5) \%42.0, Pepinoet al. (6) \%32.0 olarak saptamışlardır. Sorunlu yeme ve psikiyatrik belirtiler arasında güçlü bir ilişki mevcuttur. Depresyon ve anksiyete aşırı yeme davranışlarıyla ilişkilendirilmiştir (7). Obezite, endişe ve duygu durum bozukluklarının görülme sıklığını arttırmaktadır. Stres kaynaklı aşırı yeme ve obezite de insanlarda majör depresyon ile ilişkilidir. Kronik stres altında olan bireyler, yüksek kronik kortizol seviyelerinden dolayı daha fazla visseral yağa sahip olabilmektedir. Hiperkortizolemik depresyon, abdominal yağ birikimi, artmış kortikotropin salgilatıcı hormon (CRH) arasında doğrusal bir ilişki olduğu bildirilmektedir. Stres ile ortaya çıkan aşırı yemek yeme, bireylerin fiziksel ve psikolojik olarak yağ ve şeker bakımından zengin besinlere eğilimlerini arttırabilmektedir. $\mathrm{Bu}$ durum, duygu durum bozukluğunun, obezite üzerinde etkisini açıkça ortaya koymaktadır (8). Depresyonda iyileşme ya da kötüleşme olasılığını ve daha ileri psikolojik konsültasyonlara karar verebilmek için preoperatif dönemde hastanın psikososyal durumunun değerlendirilmesi ve postoperatif dönemde duygudurum değişikliklerinin takibinde mutlaka psikiyatri uzmanı bulunmalıdır (9).

Preoperatif dönemde günlük öğün sayısı, makromikro besin ögesi ve sıvı alımı, yeme düzeni, yeme davranışı bozuklukları ve yeme hızı gibi yeme davranışlarının ayrıntılı değerlendirmesi de postoperatif dönem için gerekli davranış değişikliklerini öğrenmek ve uygulamak için önemlidir. Diyet kalitesinin iyileştirilmesi, bariatrik cerrahinin başarısını ve hastanın operasyon sonrası dönemdeki yaşam kalitesini arttırmada etkin olmaktadır. Preoperatif dönemdeki bozulmuş beslenme durumunun, postoperatif dönemdeki besin ögesi eksiklikleri ile ilişkisinin yanında, farklı metabolik komplikasyonlarla da ilişkili olabileceği saptanmıştır (10).

Preoperatif dönemde yeme davranış bozukluklarının ve depresif semptomların varlığı ve hastaların beslenme durumu birbirinden etkilenebilmektedir. $\mathrm{Bu}$ çalışma, bariatrik cerrahi planlanan hastalarda yeme bağımlılığı, depresyon ve beslenme durumu arasındaki ilişkiyibelirlemek amacıyla yürütülmüştür. 


\section{BİREYLER VE YÖNTEM}

$\mathrm{Bu}$ araştırma, bariatrik cerrahi amacıyla özel bir kliniğe, Aralık 2019-Şubat 2020 tarihleri arasında başvuran toplam 127 hastayla yürütülmüştür. Çalışma; 18-64 yaş arası, BKİ>35 kg/m², psikiyatrik hastalığı olmayan ve ilaç kullanmayan, gebe olmayan, çalışmaya katılmaya gönüllü olan bireylerle yürütülmüştür. Araştırma için Başkent Üniversitesi Tıp ve Sağlık Bilimleri Araştırma Kurulu'ndan 19 Kasım 2019 Tarihli “KA19/369” nolu Etik Kurul Onayı alınmıştır.

Bireylerin genel özellikleri, sağlık durumları ve beslenme alışkanlıkları ile ilgili tanımlayıcı bilgileri içeren anket formu, araştırmacı tarafindan yüz yüze görüşme yöntemi ile uygulanmıştır. Bireylerin birbirini izleyen üç günlük besin tüketim kaydı alınmıştır. Kayıtların sonuçları "Beslenme Bilgi Sistemleri Paket Programı (BEBİS)” 8.1 versiyonu kullanılarak analiz edilmiştir. Analiz sonucunda bireylerin günlük tükettiği enerji ve besin ögesi miktarları hesaplanmıştır. Hesaplanan enerji ve besin ögeleri verileri “Önerilen Günlük Alım Miktarları” (Recommended Dietary Allowance-RDA)'na göre karşılaştırılmıştır (11).

Araştırmacı tarafindan antropometrik ölçümler [vücut ağırlığı (kg), boy uzunluğu (cm), bel çevresi (cm) ve kalça çevresi $(\mathrm{cm})]$ ölçülüp, beden kütle indeksi (BKI), bel/boy ve bel/kalça oranı hesaplanmıştır. Vücut ağırlığı (kg) Tanita MC780 Black vücut analiz cihazı kullanılarak, boy uzunluğu (cm) ayaklar bitişik, baş dik ve Frankfurt düzleminde (göz üçgeni ve kulak kepçesi üstü aynı hizada) olması sağlanarak stadiometre ile ölçülmüş, beden kütle indeksi (BKİ)

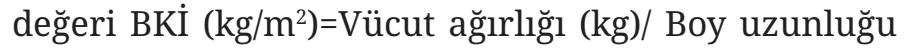
$\left(\mathrm{m}^{2}\right)$ formülü ile hesaplanmıştır. Elde edilen değer $<18.5 \mathrm{~kg} / \mathrm{m}^{2}$ ise zayıf; $18.5-24.9 \mathrm{~kg} / \mathrm{m}^{2}$ normal kilolu, $25.0-29.9 \mathrm{~kg} / \mathrm{m}^{2}$ ise fazla kilolu; $\geq 30.0 \mathrm{~kg} / \mathrm{m}^{2}$ obez olarak değerlendirilmiştir. Bireylerin bel çevresi ölçümleri alınırken kollarının iki yanda ve ayaklarının birleşik durumda olmasına dikkat edilerek, alt kaburga kemiği ile kristailiyak arası bulunup orta noktasından geçen çevre, esnek olmayan mezür ile ölçülmüştür (Kadın: $<80 \mathrm{~cm}$ normal; 80-87 cm artmış risk ; $\geq 88 \mathrm{~cm}$ yüksek risk) (Erkek: <94 cm normal; 94-101 cm artmış risk; $\geq 102 \mathrm{~cm}$ yüksek risk) (12).

Bireylerin depresyon durumlarl, Beck tarafindan 1961 yılında geliştirilen Beck Depresyon Ölçeği (BDÖ) ile belirlenmiştir. BDÖ, depresyon yönünden risk belirlemek ve depresif belirtilerin düzeyini ve şiddet değişimini ölçmek amacıyla kullanılmaktadır. Ülkemizdeki geçerlilik güvenirlik çalışması 1989 yılında Hisli tarafından yapılmıştır. Depresyon derecesi, minimal depresyon $=0-9$, hafif depresyon=10-16, orta depresyon=17-29 ve şiddetli depresyon=30-63 olarak sinıflandırılmıştır (13). Yeme bağımlılığı durumu ise, Yale Yeme Bağımlılığı Ölçeği (YYBÖ) ile değerlendirilmiştir. Son bir yıl düşünülerek, yüksek yağlı/şekerli yiyeceklerle bağımlılık benzeri yeme davranışlarını belirlemek için kullanılan 27 maddelik bir ölçek olan YYBÖ Gearhardtet al. (14) tarafindan 2009 yllında geliştirilmiştir. Bayraktar ve ark. (15) tarafından 2012 yllında Türkçe’ye uyarlanmıştır. Sevinçer ve ark. (16) tarafından da YYBÖ’nın bariatrik cerrahi hastalarında geçerlilik ve güvenilirlik çalışması yapılmıştır.

\section{Verilerin İstatistiksel Değerlendirmesi}

İstatistiksel analizler SPSS v.25.0 (IBM SPSS Statisticsfor Windows. Version 25.0.Armonk. NY: IBM Corp.) yazılımı kullanılarak yapılmıştır. Tanımlayıcı istatistikler, sayısal veriler için ortalama $(\overline{\mathrm{x}})$, standart sapma (SS), alt, üst değerler, kategorik veriler için sayı (S) ve yüzde (\%) değerleri kullanılarak özetlenmiştir. Sayısal değişkenlerde normallik varsayımı KolmogrovSmirnov ile kontrol edilmiş ve normal dağılım göstermeyen değişkenlerin karşılaştırılmasında Mann Whitney U testi kullanılmıştır. Kategorik değişkenlerin karşılaştırılmasında Pearson ki-kare veya Fisher'sexact test kullanılmıştır. İstatistik anlamlılık düzeyi 0.05 olarak belirlenmiştir. 


\section{BULGULAR}

Bireylerin cinsiyetlere göre antropometrik ölçümlerinin ortalama değerlerine ilişkin bulgular Tablo 1'de gösterilmiştir. Erkeklerin BKİ ortalaması $40.8 \pm 5.41 \mathrm{~kg} / \mathrm{m}^{2}$, kadınların BKİ ortalamasının $41.8 \pm 6.47 \mathrm{~kg} / \mathrm{m}^{2}$ olduğu belirlenmiştir (Tablo 1 ).

Bireylerin günlük diyetle aldıkları; protein, yağ, A vitamini, $\mathrm{K}$ vitamini, riboflavin, niasin, folat, $\mathrm{B}_{12}, \mathrm{C}$ vitamini, sodyum, fosfor, çinko ve bakır yüzdeleri RDA önerilerinin üzerinde olup; RDA önerilerini karşllama oranları (\%) posa hariç erkeklerde, kadınlara göre daha yüksek saptanmıştır. Hem erkek $(\% 63.3 \pm 21.32)$ hem de kadın (\%65.7ะ15.09) bireylerin günlük diyetle aldıkları potasyumun; ayrıca kadınlarda pantotenik

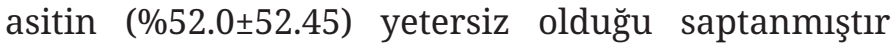
$(\mathrm{p}<0.05$, Tablo 2).

Beck Depresyon Ölçeği puan ortalaması, erkeklerde 15.2 \pm 8.21 , kadınlarda $16.8 \pm 7.30$ puan olarak saptanmıştır. Kadınlarda hafif (kadınlarda \%32.1, erkeklerde \%24.5) ve orta depresyon (kadınlarda \%51.3, erkeklerde \%42.9), erkeklerden daha fazla görülürken; minimal (erkeklerde \%26.5, kadınlarda \%14.0) ve şiddetli depresyon (erkeklerde \%6.1, kadınlarda \%2.6) erkeklerde daha yüksek saptanmıştır ( $p>0.05)$. Yeme bağımlılığı durumu ise kadınlarda (\%59.6), erkeklerden (\%40.4) daha yüksek bulunmuştur ( $p>0.05$, Tablo 3 ).

Yeme bağımlılığı olmayan bireylerin \%18.7'sinde, yeme bağımlılığı olan bireylerin \%19.1'inde minimal depresyon gözlemlenirken; yeme bağımlılığı olmayan bireylerde \%3.8, yeme bağımlılığı olanlarda ise
\%4.3 oranında şiddetli depresyonun gözlemlendiği belirtilmiştir ( $p>0.05$, Tablo 4).

Bireylerin günlük diyetle RDA'ya göre yetersiz tükettikleri pantotenik asit ve potasyumun depresyon durumlarına göre alım ortalamaları Tablo 5'te verilmiştir. Şiddetli depresyonu olan bireylerin günlük diyetle aldıkları potasyumun minimal depresyonu olan bireylere göre daha düşük olduğu saptanmıştır $(\mathrm{p}<0.05)$.

\section{TARTIŞMA}

Obezite, fiziksel ve psikolojik yansımaları ile küresel morbidite ve mortalite nedenidir. Bariatrik cerrahi, özellikle egzersiz ve tıbbi beslenme tedavisi ile yeterli vücut ağırlığı kaybı sağlayamayan bireylerde, obezite için etkili müdahalelerinden biridir (17). Bel çevresi, kalça çevresi ve bel-kalça oranı gibi ölçümlerle BKI ölçümü, artmış obezite riski ile ilişkilendirilir (18). Bu çalışmada, erkeklerin BKİ ortalaması $40.8 \pm 5.41 \mathrm{~kg} / \mathrm{m}^{2}$, kadınların ise $41.8 \pm 6.47 \mathrm{~kg} / \mathrm{m}^{2}$ bulunmuştur (Tablo 1 ).

Fazla kilolu ve obez yetişkinlerde mikro besin öğesi eksikliklerinin prevalansı da yüksek görülmektedir (19). Nedenleri çok faktörlü olmakla birlikte, en önemli sebepleri arasında; sebze ve meyve tüketiminin azalması, yüksek enerji değeri ve düşük besin kalitesine sahip besinlerin tüketiminin artması, suda çözünen vitaminler ve antioksidanlar gibi bazı besin öğelerinin depolanmasını ve vücutta bulunabilirliğini etkileyebilecek vücut yağ oranı değişiklikleri yer almaktadır (20). Bu sorun obezite

Tablo 1. Bireylerin cinsiyetlere göre antropometrik ölçümlerinin ortalama değerleri

\begin{tabular}{lcccccccc}
\hline \multirow{2}{*}{$\begin{array}{l}\text { Antropometrik } \\
\text { Ölçümler }\end{array}$} & \multicolumn{9}{c}{ Erkek (n:49) } & \multicolumn{9}{c}{ Kadın (n:78) } \\
\cline { 2 - 9 } & \multicolumn{1}{c}{ SS } & Alt & Üst & $\overline{\mathbf{x}}$ & sS & Alt & Üst \\
\cline { 2 - 9 } & 40.8 & 5.41 & 35.8 & 55.8 & 41.8 & 6.47 & 35.2 & 70.5 \\
BKI $\left(\mathrm{kg} / \mathrm{m}^{2}\right.$ ) & 132.9 & 12.12 & 108.0 & 178.0 & 125.9 & 16.11 & 93.0 & 200.0 \\
Bel çevresi (cm) & 124.7 & 14.17 & 100.0 & 177.0 & 134.1 & 16.19 & 105.0 & 222.0 \\
Kalça çevresi (cm) & 0.8 & 0.06 & 0.6 & 1.0 & 0.8 & 0.11 & 0.6 & 1.3 \\
Bel/boy oranı & 1.1 & 0.07 & 1.0 & 1.3 & 0.9 & 0.07 & 0.8 & 1.2 \\
Bel/kalça oranı & 1.1 &
\end{tabular}




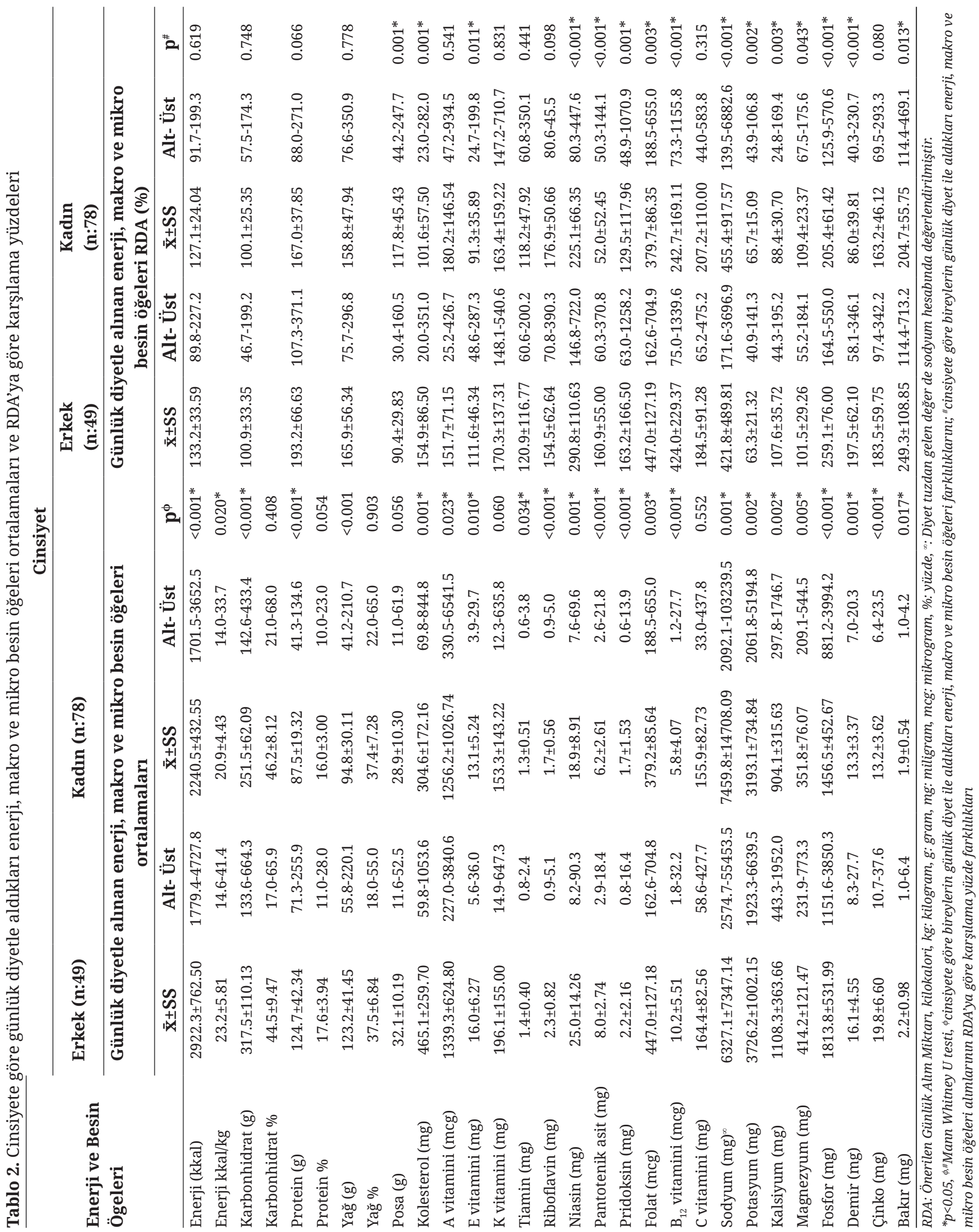


Tablo 3. Bireylerin BDÖ puanı ortalaması, depresyon ve yeme bağımlılığı durumuna göre değerlendirilmesi

\begin{tabular}{|c|c|c|c|c|c|c|c|}
\hline & \multicolumn{6}{|c|}{ Cinsiyet } & \multirow{3}{*}{$\mathbf{p}$} \\
\hline & \multicolumn{2}{|c|}{ Erkek (n:49) } & \multicolumn{2}{|c|}{ Kadın (n:78) } & \multicolumn{2}{|c|}{ Toplam (n:127) } & \\
\hline & $\mathbf{S}$ & $\%$ & $\mathbf{S}$ & $\%$ & $\mathbf{S}$ & $\%$ & \\
\hline \multicolumn{8}{|l|}{ BDÖ } \\
\hline Minimal Depresyon(0-9 puan) & 13 & 26.5 & 11 & 14.0 & 24 & 18.8 & $0.212^{\#}$ \\
\hline Hafif Depresyon(10-16 puan) & 12 & 24.5 & 25 & 32.1 & 37 & 29.3 & \\
\hline Orta Depresyon(17-29 puan) & 21 & 42.9 & 40 & 51.3 & 61 & 48.0 & \\
\hline Şiddetli Depresyon(30-63 puan) & 3 & 6.1 & 2 & 2.6 & 5 & 3.9 & \\
\hline BDÖ puan ortalaması ( $\overline{\mathrm{X}} \pm \mathrm{SS})$ & \multicolumn{2}{|c|}{$15.2 \pm 8.21$} & \multicolumn{2}{|c|}{$16.8 \pm 7.30$} & \multicolumn{2}{|c|}{$16.2 \pm 7.67$} & $0.228^{\mu}$ \\
\hline \multicolumn{8}{|l|}{ Yeme Bağımlılığı Durumu } \\
\hline Var & 19 & 40.4 & 28 & 59.6 & 47 & 37 & $0.851^{\#}$ \\
\hline Yok & 30 & 37.5 & 50 & 62.5 & 80 & 63 & \\
\hline
\end{tabular}

BDÖ: Beck Depresyon Ölçeği, \#Fisher's Exact Ki-Kare Testi, $\mu$ MannWhitney U testi

Tablo 4. Bireylerin yeme bağımlılığı durumuna göre depresyon durumlarının dağılımı

\begin{tabular}{|c|c|c|c|c|c|c|c|}
\hline \multirow{3}{*}{$\begin{array}{l}\text { Depresyon } \\
\text { Durumu }\end{array}$} & \multicolumn{6}{|c|}{ Yeme bağımlılığı } & \multirow{3}{*}{$\mathbf{p}$} \\
\hline & \multicolumn{2}{|c|}{$\begin{array}{c}\text { Yeme Bağımlılığı } \\
\text { Durumu Olmayanlar }\end{array}$} & \multicolumn{2}{|c|}{$\begin{array}{l}\text { Yeme Bağımlılığı } \\
\text { Durumu Olanlar }\end{array}$} & \multicolumn{2}{|c|}{ Toplam } & \\
\hline & $\mathbf{S}$ & $\%$ & $\mathbf{S}$ & $\%$ & $\mathbf{S}$ & $\%$ & \\
\hline Minimal Depresyon & 15 & 18.7 & 9 & 19.1 & 24 & 18.9 & $0.484^{\#}$ \\
\hline Hafif Depresyon & 27 & 33.7 & 10 & 21.3 & 37 & 29.1 & \\
\hline Orta Depresyon & 35 & 43.8 & 26 & 55.3 & 61 & 48.1 & \\
\hline Şiddetli Depresyon & 3 & 3.8 & 2 & 4.3 & 5 & 3.9 & \\
\hline Depresyon skoru $(\overline{\mathrm{X}} \pm \mathrm{SS})$ & \multicolumn{2}{|c|}{$15.8 \pm 7.31$} & \multicolumn{2}{|c|}{$17.0 \pm 8.28$} & \multicolumn{2}{|c|}{$16.2 \pm 0.71$} & $0.399^{\mu}$ \\
\hline
\end{tabular}

\#Fisher's Exact Ki-Kare Testi, $\mu$ Bağımsız örneklem t testi

Tablo 5. Bireylerin depresyon durumuna göre günlük diyetle tükettikleri yetersiz besin ögeleri alım ortalamaları

\begin{tabular}{lccccc}
\hline RDA (\%) yetersiz & \multicolumn{5}{c}{ BDÖ } \\
\cline { 2 - 6 } besin ögeleri & Minimal Depresyon & Hafif Depresyon & Orta Depresyon & Şiddetli Depresyon & $\mathbf{p}^{\#}$ \\
\hline Pantotenik asit (mg) & $7.1 \pm 2.97$ & $6.3 \pm 1.99$ & $6.8 \pm 2.86$ & $9.2 \pm 5.28$ & 0.183 \\
Potasyum (mg) & $3497.4 \pm 835.11$ & $3266.9 \pm 803.92$ & $3488.7 \pm 963.57$ & $2804.0 \pm 213.12$ & 0.113 \\
\hline RDA:Ön
\end{tabular}

RDA: Önerilen Günlük Alım Miktarı,mg: miligram, BDÖ: Beck Depresyon Ölçeği, \# Mann Whitney U testi

nedeniyle, bariatrik cerrahi adaylarında da benzerdir. Bariatrik cerrahi adayı olan obez bireylerin beslenme durumunun genellikle düzensiz ve dengesiz; vitaminler ve mineraller yönünden de diyetlerinin yetersiz olduğu bildirilmiştir (21). Bunun aksine obez bireylerin günlük almış oldukları muhtemel enerji fazlalığına bağlı olarak da makro ve mikro besin öğesi gereksinmelerinin önerilerin üzerine çıkabileceği de ifade edilmektedir (22).

Bireylerin günlük diyetle aldıkları A (erkeklerde $\% 151.7 \pm 71.15 ; \quad$ kadınlarda $\% 180.2 \pm 146.54)$ ve $\mathrm{K}$ vitamini miktarları (erkeklerde \%170.3 \pm 137.31 , kadınlarda \%163.4 \pm 159.22$) \quad$ RDA önerilerinin üzerindedir. Yapılan bir araştırmada preoperatif dönemde, hastaların günlük diyetle tükettikleri yağda çözünen vitaminlerin (A, D, E) yeterli düzeyde olmadığı saptanmıştır (23).

Çalışmaya katılan kadınların günlük diyetle aldıkları potasyum (kadınlarda \%65.7 \pm 15.09 , erkeklerde \%63.3 \pm 21.32 ) RDA önerilerini karşllamamaktadır (Tablo 2). Bariatrik cerrahi planlanan morbid obez hastaların \%71.5’inin potasyum, \%74.0’ünün 
kalsiyum ve \%33.8'inin demiri yetersiz düzeyde aldığı bulunmuştur (23). Amerika Birleşik Devletleri'nde yetişkin obez bireylerin beslenmesinin, birçok vitamin ve mineral açısından zengin olan meyve, sebze, süt ürünleri, tam tahıl, kuruyemiş, kurubaklagil, balık gibi besinler açısından yetersiz olduğu belirlenmiştir (24). Şekerli içeceklerin artan tüketimi, süt tüketiminde azalmaya; dolayısıla kalsiyum eksikliğine neden olabilmektedir (25). Obez bireylerin, fiziksel aktivitesinde azalma güneş ışığına maruziyeti azaltarak, D vitamini eksikliğine de neden olabilmektedir. Ayrıca derialtı yağ dokusu fazlalığı sonucu D vitamini sentezi de azalmaktadır (26).

Bariatrik cerrahi öncesinde hastalarda mikrobesin öğeleri eksikliklerini araştıran bir çalışmada, kadınlarda erkeklere kıyasla eksikliğin daha fazla olduğu görülmüş; preoperatif D vitamini eksikliği \%2276, demir eksikliği \%6-50.5, folat eksikliği \%0-56 ve demir yetersizliğine bağlı anemi prevalansı\%15.8-19.6 olarak belirlenmiştir (10).

Preoperatif dönemde var olan besin öğesi eksiklikleri, bariatrik cerrahi nedeniyle gelişebilecek malabsorbsiyon ile birleşerek, hastaların postoperatif geç dönemde, özellikle mikro besin ögelerinde yetersizliğe neden olabilmektedir (27). Besin ögesi eksiklikleri, operasyon sonrası dönemde komplikasyonlara bağlı olarak da gelişebilmektedir. Bunlardan birisi, hem kısıtlayıcı hem de malabsorbtif cerrahi operasyonlar sonrası gelişebilen tiamin eksikliğidir. Bununla birlikte hastaların tiamin kaynağı olmayan rafine şekerlerden ve beyaz pirinçten elde edilen yüksek karbonhidrat alımına sahip olmaları nedeniyle, eksikliğin ameliyat öncesi dönemden kaynaklanacağı da belirtilmektedir (28). Bu çalışmaya katılan bireylerin günlük diyetle aldıkları tiamin miktarları kadınlarda $1.3 \pm 0.51 \mathrm{mg}$, erkeklerin ise $1.4 \pm 0.40 \mathrm{mg}$ 'dır ve RDA önerilerini karşıladığı saptanmıştır (Tablo 2).

Flancbaumet al. (29), yaptıkları çalışmada, hastaların preoperatif dönemde \%43.9'unda demir, \%8.4'ünde ferritin, kadınların \%22'sinde, erkeklerin \%19.1'inde hemoglobin, \%29'unda tiamin ve \%68.1'inde D vitamini eksiklikleri olduğunu belirlemiş; ferritin düşüklüğünün kadınlarda, aneminin ise erkeklerde daha yaygın olduğunu rapor etmiştir. Obez kadınlarda bariatrik cerrahi öncesi mikro besin ögeleri durumunu belirlemek amacıyla yapılan bir çalışmada da; \%73.9 çinko, \%67.8 bakır ve \%25.2 oranında folik asit eksikliği belirlenmiştir (30).

Bariatrik cerrahi öncesinde mikro ve makro besin ögeleri eksiklikleri cerrahinin, kısa, orta ve uzun vadede başarısını olumsuz etkileyebilir. Bununla birlikte, preoperatif dönemde var olan besin ögesi eksiklikleri postoperatif dönemde daha da ağır hale gelebileceğinden; eksikliklerin preoperatif dönemde giderilmesi önemlidir (31).

Bariatrik cerrahi öncesinde beslenme durumunun değerlendirilmesi, cerrahinin başarını etkilemesinin yanında postoperatif dönemde kronik metabolik komplikasyonların da gelişmesini engelleyebilmektedir (32). Obez bireyler yüksek depresyon riski altında olup; depresif bireyler de obezite için yüksek risk altındadır. Dolayısıyla obezite ve depresyon arasındaki neden-sonuç ilişkisi karşılıklıdır (17). Morbid obezite, depresyon ve düşük benlik saygısı gibi psikososyal sonuçlarla da ilişkilidir. Morbid obez hastaların depresif, endişeli, zayıf dürtü kontrolü, düşük benlik saygısı ve bozulmuş yaşam kalitesine sahip oldukları düşünülmektedir (33).

$\mathrm{Bu}$ çalışmaya katılan bireylerin BDÖ depresyon skoru ortalaması yeme bağımlılığı durumu olanlarda 17.0 \pm 8.28 puan, yeme bağımlılığı durumu olmayanlarda 15.8 \pm 7.31 puan olarak belirlenmiştir ( $>0.05$, Tablo 4). Yeme bağımlılığı olan ve olmayan gruplarda, minimal, hafif, orta ve şiddetli depresyon durumu benzer bulunmuştur $(p>0.05)$. Bariatrik cerrahi adayı bireyler ile yapılan bir çalışmada, hastaların \%46.6'sında tıkınırcasına yeme bozukluğu olduğu, depresyonu olan hastalarda, depresyonu olmayanlara göre yeme bozukluğunun daha şiddetli olduğu bulunmuştur (34). Bu sonuca benzer şekilde, ABD'de bariatrik cerrahi planlanan bireylerle yapılan bir çalışmada, tıkınırcasına yeme bozukluğu olan bireylerin BDÖ puanlarının, olmayanlara göre 
daha yüksek olduğu bulunmuştur (35). White et al. (36), bariatrik cerrahi adaylarının yaklaşık \%22.445.0'inde anksiyete/depresyon bulgularının varlığını bildirmektedir. Bariatrik cerrahi adaylarında yapılan çalışmaların meta-analizinde, bireylerin \%20-50'sinin, depresyon ve duygudurum bozuklukları öyküsü olduğu ve duygudurum bozuklukları sıklıklarının genel popülasyona göre daha fazla olduğu, postoperatif birinci yllda ise depresyonun hem prevalansında hem de şiddetinde önemli iyileşmeler olduğu bildirilmiştir (37).

$\mathrm{Bu}$ çalışmada şiddetli depresyonda olan bireylerin, minimal depresyonda olan bireylere göre diyetle potasyum alımlarının daha düşük olduğu saptanmıştır ( $>$ >0.05,Tablo5). Sekizyıltakipliyapılanbiraraştırmada ise potasyum içeriği de yüksek olan Hipertansiyonu Durdurmaya Yönelik Diyet Yaklaşımları (Dietary Approaches to Stop Hypertension/DASH) diyetinin uygulanmasiyla depresyon insidansinda azalma saptanmıştır (38). Yapılan bir araştırmada, günlük diyetle kalsiyum alımları $<1000 \mathrm{mg}$ olan bireylerde depresyon sıklığının daha yüksek saptandığı belirtilmiştir (39). Demir alımı ve depresyon ilişkisini inceleyen bir diğer araştırmada ise, demir tüketimi en yüksek olan grupta, daha düşük alıma sahip gruplara göre istatistiksel açıdan anlamlı olarak daha düşük depresyon riskinin olduğu saptanmıştır (40).

Sonuç olarak ciddi morbidite ve mortalite yükü taşıyan obezite, mutlak olarak tedavi edilmesi gereken kronik bir hastalıktır. Obezitenin tedavisinde son dönemde sıklıkla başvurulan bariatrik cerrahi ise endike durumlarda uygulanmalıdır. Ancak bariatrik cerrahi, aşırı şişmanlıktan kurtulmak için kolay ve mucizevi bir tedavi yöntemi değildir. Bariatrik cerrahi yöntemleri kısa dönemde hızlı vücut ağırlığı kaybı sağlamakla birlikte, önemli metabolik komplikasyonlara neden olabilmektedir. Bariatrik cerrahinin başarısının operasyon sonrasında devamlılığı için yeni yaşam tarzı değişikliklerine sıkı uyum çok önemlidir. Bu yüzden hastanın operasyon öncesinde multidisipliner bir ekip tarafından değerlendirilmesi; hastanın operasyon sonrasında yaşam tarzı değişikliklerine uyumu zorlaştıracak yeme bağımlılığı, depresyon ve beslenme durumu gibi belirteçlerin gözden geçirilmesi, operasyonun başarısı açısından oldukça önem arz etmektedir.

Yazarlık katkısı - Author contributions: Çalışmanın tasarımı verilerin elde edilmesi, verilerin analiz edilmesi, makale yazımı: İA; Çalışmanın tasarımı, verilerin analiz edilmesi, makale yazımı ve makale onayı: EKB - Study design, obtaining study data, analyzing data article writing: İA; Study design, analyzing data article writing and approval EKB.

Etik Kurul Onayı - Ethics approval: Araştırma için Başkent Üniversitesi Tip ve Sağllk Bilimleri Araştırma Kurulu’ndan 19 Kasım 2019 Tarihli “KA19/369” nolu Etik Kurul Onay alınmıştır.

Çıkar çatışması - Conflict of interest: Yazarlar çıkar çatışması olmadığını beyan ederler. - The authors declare that they have no conflict of interest.

\section{KAYNAKLAR}

1. Polikandrioti M, Stefanou E. Obesity disease. Health Science Journal. 2009;3(3):132-6.

2. Chu DT, Nguyet NTM, Dinh TC, Lien NVT, Nguyen KH, Ngoc VTN, et al. An update on physical health and economic consequences of overweight and obesity. Diabetes Metab Syndr. 2018;12:1095-5.

3. Nguyen NT, Varela JE. Bariatric surgery for obesity and metabolic disorders: State of the art. Nat Rev Gastroenterol Hepatol. 2017;14(3):160-9.

4. Lerma-Cabrera JM, Carvajal F, Lopez-Legarrea P. Food addiction as a new piece of the obesity framework. Nutr J. 2016;15(5):1-5.

5. Meule A, Heckel D, Kübler A. Factor structure and item analysis of the Yale Food Addiction Scale in obese candidates for bariatric surgery. Eur Eat Disord Rev. 2012;20(5):419-3.

6. Pepino MY, Stein RI, Eagon JC, Klein S. Bariatric surgery-induced weight loss causes remission of food addiction in extreme obesity. Obesity (Silver Spring). 2014;22(8):1792-6.

7. Miller-Matero LR, Armstrong R, McCulloch K, HydeNolan M, Eshelman A, Genaw J. To eat or not to eat; is that really the question? An evaluation of problematic eating behaviors and mental health among bariatric surgery candidates. Eat Weight Disord. 2014;19(3):377-5.

8. Singh M. Mood, food, and obesity. Front Psychol. 2014;5:925. 
9. Ayloo S, Thompson K, Choudhury N, Sheriffdeen R. Correlation between the Beck Depression Inventory and bariatric surgical procedures. Surgery for Obesity and Related Diseases. 2015;11(3):637-5.

10. Sherf-Dagan S, Sinai T, Goldenshluger A, Globus I, Kessler Y, Schweiger C, et al. Nutritional assessment and preparation for adult bariatric surgery candidates: Clinical practice. Adv Nut.2021;12(3):1020-11.

11. What are the Recommended Dietary Allowances (RDAs) and the Dietary Reference Intakes (DRIs)? Available at: https://www.nal.usda.gov/fnic/what-are-recommendeddietary-allowances-rdas-and-dietary-reference-intakesdris Accessed February 25, 2021.

12. WHO. Obesity: preventing and managing the global epidemic. Report of a WHO Consultation. WHO Technical Report Series 894. Geneva, 2000. Available at: https://www.who.int/nutrition/publications/obesity/ WHO_TRS_894/en/ Accessed February 2, 2021.

13. Hisli N. Beck Depresyon envanterinin üniversite öğrencileri için geçerliği, güvenilirliği. Psikoloji Dergisi. 1989;23(7):3-10.

14. Gearhardt AN, Corbin WR, Brownell KD. Preliminary validation of the Yale Food Addiction Scale. Appetite. 2009;52(2):430-6.

15. Bayraktar F, Erkman F, Kurtulus E. Adaptation study of Yale food addiction Scale. Klinik Psikofarmakol Bülteni. 2012;22(1):38.

16. Sevinçer G, Konuk N, Bozkurt S, Saracli O, Coşkun H. Psychometric properties of the Turkish version of the Yale Food Addiction Scale among bariatric surgery patients. Anadolu Psikiyatri Derg. 2015;16:44-7.

17. Alosco ML, Spitznagel MB, Strain G, Devlin M, Cohen R, Crosby RD, et al. Pre-operative history of depression and cognitive changes in bariatric surgery patients. Psychol Health Med. 2015;20(7):802-11.

18. World Health Organization. Waist circumference and waist-hip ratio: Report of a WHO expert consultation. 2011. $39 \mathrm{p}$.

19. Kaidar-Person O, Rosenthal RJ. Malnutrition in morbidly obese patients: Fact or fiction? Minerva Chir. 2009;64(3):297-5.

20. Gillis L, Gillis A. Nutrient inadequacy in obese and nonobese youth. Can J Diet Pract Res. 2005;66(4):237-5.

21. Love AL, Billett HH. Obesity, bariatric surgery, and iron deficiency: True, true, true and related. Am J Hematol. 2008;83(5):403-6.

22. Richards TJ, Patterson PM, TegeneA. Obesity and nutrient consumption: A rational addiction? Contemp Econ Policy. 2007;25(3):309-15.

23. Correia Horvath JD, Dias de Castro ML, Kops N, Kruger Malinoski N, Friedman R. Obesity coexists with malnutrition? Adequacy of food consumption by severely obese patients to dietary reference intake recommendations. Nutr Hosp. 2014;29(2):292-7.

24. Kant AK. Reported consumption of low-nutrient-density foods by American children and adolescents: Nutritional and health correlates, NHANES III, 1988 to 1994. Arch Pediatr Adolesc Med. 2003;157(8):789-7.

25. Keller KL, Kirzner J, Pietrobelli A, St-Onge MP, Faith MS. Increased sweetened beverage intake is associated with reduced milk and calcium intake in 3- to 7-yearold children at multi-item laboratory lunches. J Am Diet Assoc. 2009;109(3):497-4.

26. Wachs TD. Multiple influences on children's nutritional deficiencies: A systems perspective. Physiology\&Behavior. 2008;94(1):48-12.

27. Schilling PL, Davis MM, Albanese CT, Dutta S, Morton J. National trends in adolescent bariatric surgical procedures and implications for surgical centers of excellence. J Am Coll Surg. 2008;206(1):1-12.

28. Carrodeguas L, Kaidar-Person O, Szomstein S, Antozzi P, Rosenthal R. Preoperative thiamine deficiency in obese population undergoing laparoscopic bariatric surgery. Surg Obes Relat Dis. 2005;1(6):517-5.

29. Flancbaum L, Belsley S, Drake V, Colarusso T, Tayler E. Preoperative nutritional status of patients undergoing Roux-en-Y gastric bypass for morbid obesity. J Gastrointest Surg. 2006;10(7):1033-4.

30. de Luis DA, Pacheco D, Izaola O, Terroba MC, Cuellar L, Cabezas G. Micronutrient status in morbidly obese women before bariatric surgery. Surg Obes Relat Dis. 2013;9(2):323-4.

31. Valentino D, Sriram K, Shankar P. Update on micronutrients in bariatric surgery. Curr Opin Clin Nutr Metab Care. 2011;14(6):635-6.

32. Schneider A, Hutcheon DA, Hale A, Ewing JA, Miller M, Scott JD. Postoperative outcomes in bariatric surgical patients participating in an insurance-mandated preoperative weight management program. Surg Obes Relat Dis. 2018;14(5):623-7.

33. van Hout GC, Verschure SK, van Heck GL. Psychosocial predictors of success following bariatric surgery. Obes Surg. 2005;15(4):552-8.

34. Horvath JD, Kops NL, de Castro ML, Friedman R. Food consumption in patients referred for bariatric surgery with and without binge eating disorder. Eat Behav. 2015;19:173-3.

35. Jones-Corneille LR, Wadden TA, Sarwer DB, Faulconbridge LF, Fabricatore AN, Stack RM, et al. Axis I psychopathology in bariatric surgery candidates with and without bingeeating disorder: Results of structured clinical interviews. Obes Surg. 2012;22(3):389-8. 
36. White MA, Kalarchian MA, Levine MD, Masheb RM, Marcus MD, Grilo CM. Prognostic significance of depressive symptoms on weight loss and psychosocial outcomes following gastric bypass surgery: A prospective 24-month follow-up study. Obes Surg. 2015;25(10):190916.

37. Dawes AJ, Maggard-Gibbons M, Maher AR, Booth MJ, Miake-Lye I, Beroes JM, et al. Mental health conditions among patients seeking and undergoing bariatric surgery. JAMA. 2016;315(2):150-13.

38. Perez-Cornago A, Sanchez-Villegas A, Bes-Rastrollo M, Gea A, Molero P, Lahortiga-Ramos F, et al. Relationship between adherence to Dietary Approaches to Stop
Hypertension (DASH) diet indices and incidence of depression during up to 8 years of follow-up. Public Health Nutr. 2017;20(13):2383-9.

39. Alkhatatbeh MJ, Khwaileh HN, Abdul-Razzak KK. High prevalence of low dairy calcium intake and association with insomnia, anxiety, depression and musculoskeletal pain in university students from Jordan. Public Health Nutr. 2020;24(7):1778-8.

40. Li Z, Wang W, Xin X, Song X, Zhang D. Association of total zinc, iron, copper and selenium intakes with depressionin the US adults. J Affect Disord. 2018;228:5816. 